\title{
Assessing the Correlation between Forest Degradation and Climate Variability in the Oluwa Forest Reserve, Ondo State, Nigeria
}

\author{
Felix Ndukson Buba ${ }^{1}$, Efron Nduke Gajere ${ }^{2}$, Ferdinand Fang Ngum ${ }^{3}$ \\ ${ }^{1}$ African Regional Centre for Space Science and Technology Education in English (ARCSSTE-E), Obafemi Awolowo University \\ Campus, Ile-Ife, Nigeria \\ ${ }^{2}$ National Centre for Remote Sensing (NCRS), Jos, Nigeria \\ ${ }^{3}$ Societe d'Exploitation Forester Yond Dong (SEFYD), Congo Brazzaville \\ Email: ^bubadillo@gmail.com
}

How to cite this paper: Buba, F. N., Gajere, E. N., \& Ngum, F. F. (2020). Assessing the Correlation between Forest Degradation and Climate Variability in the Oluwa Forest Reserve, Ondo State, Nigeria. American Journal of Climate Change, 9, 371-390. https://doi.org/10.4236/ajcc.2020.94023

Received: June 15, 2020

Accepted: November 20, 2020

Published: November 23, 2020

Copyright $\odot 2020$ by author(s) and Scientific Research Publishing Inc. This work is licensed under the Creative Commons Attribution International License (CC BY 4.0).

http://creativecommons.org/licenses/by/4.0/

\begin{abstract}
Between 1981 and 1994, Nigeria lost 3.7 million hectares of its forests. It is estimated that less than $4 \%$ of Nigeria's rainforest cover is left. Reckless use and abuse of the forest reserves in Nigeria lead to degradation. However, the relationship between forest degradation and climate variability has not been clearly elucidated. This study assesses the trend of forest degradation between 1986, 2002 and 2014 in the study area and also examines the correlation between forest degradation and climate variability using temperature and rainfall parameters. Classification of Landsat images (TM 1986, ETM+2002, and OLI 2014) and change analysis using NDVI values of three-timed period were performed to observe forest degradation in the study area. NDVI values were calculated by combining bands 4 (near infrared) and 3 (visible red) for Landsat TM and ETM+ and bands 5 (near infrared) and 4 (visible red) for Landsat OLI using the spatial analysis extension in ArcGIS environment Linear regression statistical analysis was employed to determine the correlation between forest degradation and climate variability. The results show a fluctuation in the trend of forest degradation, while a positive correlation coefficient of 0.58 shows that there is a relationship between forest degradation and temperature and rainfall variability. The study concludes that though there is a positive correlation between forest degradation and climate variability in the study area, the relationship is weak and not strong enough to make generalizations.
\end{abstract}

\section{Keywords}

Forest Degradation, Temperature, Rainfall, NDVI, Regression Analysis 


\section{Introduction}

Nigeria's population is estimated to be above 180 million, with a majority of the people living in rural areas. The forest ecosystem, by virtue of its location and the many goods and services it can supply "for free", is highly depended upon for daily sustenance and livelihood by rural communities and, indeed, humanity. According to the Centre for People and Forests (2012), more than 1.6 billion people worldwide depend on forest resources for their livelihoods. Forests provide us with a wide range of goods and services, some of which include food, shelter, timber, paper, non-wood forest products such as medical plants, and other daily needs. They serve as wildlife habitat, preserving biodiversity and providing essential ecosystem services such as pollination (birds, bats, and insects), decomposition (important for soil arthropods, fungi, and micro-organisms), seed dispersal (insects and birds), etc. Forests also modify temperature and affect rainfall through evapotranspiration, and they act as "carbon sinks", taking up carbon dioxide from the atmosphere (Food and Agriculture Organization, 2011).

Given the contribution of forests to sustainable development and their role in ensuring human well-being, the state of the forests is important to all of us. Perhaps, a lack of adequate information coupled with many other factors is responsible for the degradation and reckless use of the forest ecosystem. According to FAO (cited in Tovar, 2009), a forest is a land that encompasses more than 0.5 hectares, with trees greater than $5 \mathrm{~m}$ in height, and with crown coverage of at least $10 \%$. It does not include vegetation coverage in agricultural zones nor does it include parks or gardens in urban areas. Deforestation is defined as the transformation of forests to other land uses or the reduction, over large tracts, of the crown coverage to less than the minimum of $10 \%$ coverage. This implies serious or permanent loss of forest coverage and the transformation of forests into lands dedicated to other uses. On the other hand, forest degradation is the alteration of the condition of the forest resulting in a change (as opposed to loss) or reduction in the coverage without necessarily a loss from its original condition but a negative change to its structure (loss of biodiversity or a decrease in biomass) that diminishes its capacity to generate services and products (Tovar, 2009).

Societies have pursued the objectives of economic growth and material progress, but adverse effects have also been generated (Archana, 2013). Deforestation and forest degradation are some of the environmental consequences of such a quest. The implication of the abuse of forests is seen in form of climate change, food insecurity, decrease in agricultural productivity and poverty. Economic development that destroys habitats and impairs services will create cost to humanity in the long term that may greatly exceed the short-term economic benefits (Loreau et al., 2001). One of such costs is the loss of biodiversity. Forests are among the most biologically diverse ecosystems on the planet as over half of all terrestrial species live in rainforests (Senior et al., 2017). Loss of habitats will lead to loss of species, affecting the balance in the ecosystem and loss of products and services performed by such species. 
Equally important is the effect of forests on climate where forest loss leads to dire consequences. Climate change has become a serious concern worldwide owing to its multi-faceted impact upon the physical as well as socio-economic environment as a result of which natural hazards and extreme climatic events are expected to occur more frequently (Kundu et al., 2017). There are several mechanisms through which forests affect weather and climate. One such mechanism is evapotranspiration. Evapotranspiration (water that evaporates from the forest back to the atmosphere) is an essential part of the water cycle as it increases rainfall across nearby ecosystems. Forests, through the process of evapotranspiration, also maintain cloud cover and increase the level of vapor in the atmosphere which cools the air (CPF, 2012). Tropical forests cool climate via their very high transpiration rates: the moisture transferred to the atmosphere forms large clouds which reflect incoming radiation (solar energy) and cause a further cooling (Sanderson et al., 2012). Loss of forests disrupts this cycle resulting in less rainfall and causing drier conditions, sometimes leading to droughts.

Another mechanism through which forests or loss of forests affect climate is the direct absorption and reflection of solar radiation. The earth's surface reflects and absorbs different portions of the radiation it receives. Temperature depends on the amount of radiation reaching the surface of the earth, governed principally by vegetation. Vegetation influences temperature through direct absorption and reflection of incident solar radiation and through evapotranspiration by determining the amount of thermal energy dissipated through the evaporation of water (Senior et al., 2017). Forests absorb more radiation than plains. Radiation that is not absorbed is reflected back into the atmosphere. Changes in land use can profoundly influence vegetation cover, which tends to increase temperature. Deforestation and degradation of the forests cause land to reflect more radiation, altering the air currents above and increasing the variation of local temperature (Senior et al., 2017).

The effect of land use changes on temperature was demonstrated by Senior et al. (2017) in a study that analyzed the impacts of forest degradation and conversion on local temperature. Using temperature data from paired sites that differed in land use type (primary forest, degraded forest, plantation, pasture, and cropland), the study found that degradation and deforestation cause a lowering and thinning of the canopy, and reduction in rooting depth, leaf area index, and surface roughness, all of which reduce evapotranspiration and thereby increase temperature. The study also found that changes to canopy architecture and a reduction in the number of subcanopy vegetation strata also cause warming by increasing the amount of solar radiation reaching the ground. The study found that altered land use types were substantially hotter than primary forests and therefore concluded that land use change increases local temperature in the tropics.

Also related to temperature, another mechanism whereby forests affect climate is through carbon sequestration. All plant life absorbs carbon dioxide $\left(\mathrm{CO}_{2}\right)$ and releases oxygen as part of natural metabolic processes. Forests are no exception as the trees and other plant life in a forest can take in and store $\mathrm{CO}_{2}$, a 
process called carbon sequestration (Senior et al., 2017). Therefore all forests contain large amounts of carbon and loss of forests both releases $\mathrm{CO}_{2}$ from the plants that are cut down and removes their ability to sequester carbon. Also, the burning or decomposition of destroyed forest matter releases this carbon into the atmosphere in the form of $\mathrm{CO}_{2}$ which, being a greenhouse gas, absorbs solar heat within the atmosphere. Increased concentration of $\mathrm{CO}_{2}$ and other greenhouse gases make our atmosphere store more heat from the sun thereby increasing the temperature on earth resulting in global warming (CPF, 2012). It is estimated that the earth is warming at about $0.3^{\circ} \mathrm{C}$ increase per decade, due to the increase in the amount of $\mathrm{CO}_{2}$ present in the atmosphere (Tejasmi, 2007). Deforestation in different parts of the world contributes $12 \%$ - $17 \%$ of global $\mathrm{CO}_{2}$ emissions each year (CPF, 2012). Uptake of $\mathrm{CO}_{2}$ by forests reduces its levels in the atmosphere and results in a net cooling and slowing down the effects of climate change.

As already noted, about 1.6 billion people in the world depend on forest and forest-based resources for their livelihood. Across the tropics, forest inhabitants depend entirely on forest-based resources for their livelihood. However between 1990 and 1995, the total number of forests decreased by 56.3 million hectares (FAO, 2005). At this rate, the 1.7 billion hectares tropical forest present in Asia, Africa and Latin America will disappear by the end of the $21^{\text {st }}$ century (FAO, 2005). Forests in Nigeria are not left out of this global trend. Presently, Nigeria's forests harbor about 4000 different species of plants, including those with medicinal value, with various plants used as anti-infective agents, anti-malarial remedies, laxatives, cardiovascular and nervous remedies, etc. (Gbile \& Adesina, 1987). There are also animals, including birds that are rare. These include the Ibadan Malimbe, the Anambra waxbill, the Jos indigo bird, the white-throated monkey, the Niger Delta pigmy hippo and the Niger Delta colobus monkey (Orimoogunje, 2005). Further loss of forests will lead to the extinction of these rare fauna.

Between 1981 and 1994, Nigeria lost 3.7 million hectares of its forest, and presently, less than $4 \%$ of Nigeria's untouched rainforest cover is left (Orimoogunje, 2005). This implies a colossal loss of biodiversity. The greatest threats to forests in Nigeria have been bush burning, encroachment for settlements and agriculture, and illegal logging. Forest reserves were established in Nigeria to serve as repositories of the primary habitats of the forest ecosystems. However, incursions and encroachment by peasant farmers into these reserves are recurring as a consequence of increasing population pressure and the need to feed the population (Salami et al., 1999). The degradation process in the forest reserves in southwestern Nigeria has been found to be significant in terms of the disappearance of the three crown layers of trees characteristic to the region (Ekanade, 1997; Salami et al., 1999). At the present, the Oluwa forest reserve is under attack both from within and from without. This is due to the need of meeting the ever increasing demands for forest products and for agriculture as population increases.

This increasing demand may result in change in the climatic conditions of Oluwa forest reserve and the surrounding environment and communities. Most studies on climate and vegetation in Nigeria focus on the effects and impacts of 
climate variables such as rainfall and temperature on vegetation and productivity. The present study made an attempt to reverse this trend by assessing the correlation between forest degradation (vegetation reduction due to farm and settlement encroachment and illegal logging) and climate variability, using rainfall and temperature. Examining the impact of degradation on rainfall is very vital because the communities surrounding the study area are agrarian societies and any fluctuations in rainfall will have devastating effects on food security. As for temperature, it is known to be an important factor affecting vegetation greenness. The research therefore evaluated the trend of vegetation degradation between 1986, 2002 and 2014 and also examined the correlation between such degradation and climate variability.

\section{Materials and Methods}

\subsection{Study Area}

Oluwa forest reserve is one of a number of forest reserves located in Ondo State, southwestern part of Nigeria (see Figure 1). It lies approximately between latitudes $6^{\circ} 37^{\prime}$ and $7^{\circ} 20^{\prime}$ North and longitudes $4^{\circ} 27^{\prime}$ and $5^{\circ} 05^{\prime}$ East (Orimoogunje, 2014). Originally part of the Omo-Shasha-Oluwa forest reserve, the Oluwa reserve has been separated from the Omo and Shasha reserves, and now covers over $829 \mathrm{~km}^{2}$. The three reserves contain some of the last remaining forests in the area but are presently threatened by logging, hunting and agriculture, especially tree crops (cocoa) and arable crop cultivation (Orimoogunje, 2014). Oluwa forest reserve is located $50 \mathrm{~km}$ east of Omo and $26 \mathrm{~km}$ from Ore town, with an undulating topography and a mean elevation of $90 \mathrm{~m}$ above sea level, mean relative humidity of $80 \%$, and a daily temperature of $25^{\circ} \mathrm{C}$, characterized by a moist semi-evergreen rainforest (Udoakpan, 2013). The study area has an annual rainfall which exceeds $2000 \mathrm{~mm}$ with two distinct seasons: the rainy season which starts mostly in February and ends in October and a dry season that starts in November and ends in January.

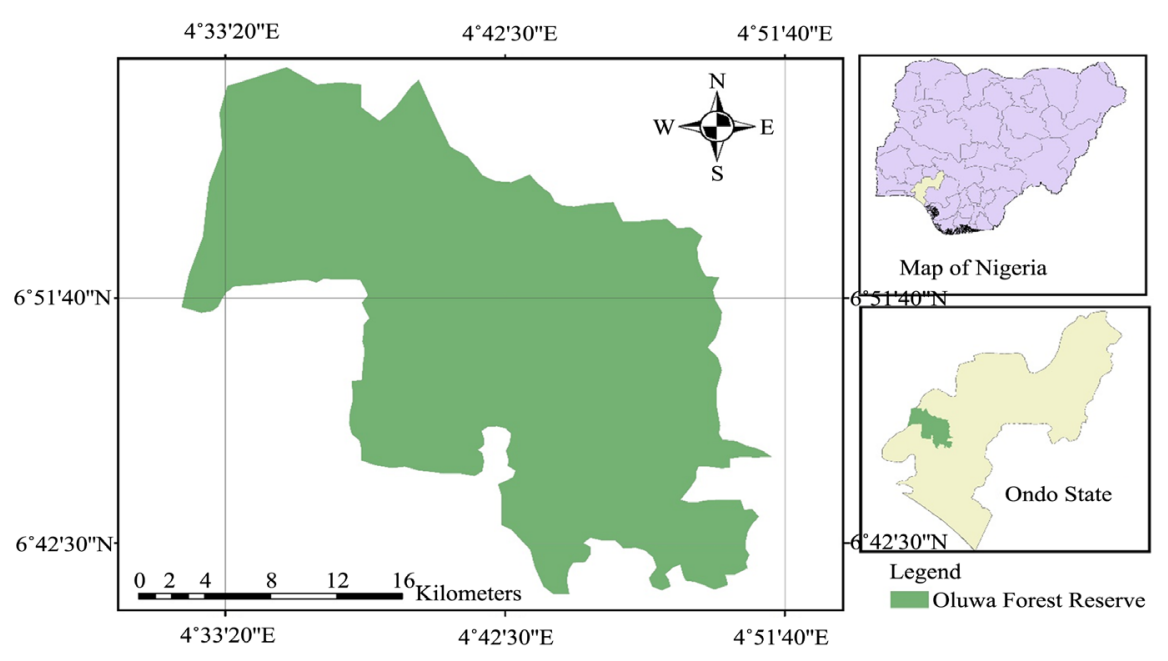

Figure 1. Map of the study area. 


\subsection{Materials and Data Requirements}

To assess the trend of vegetation degradation, Landsat Thematic Mapper (TM) image of $5^{\text {th }}$ January 1986, Enhanced Thematic Mapper (ETM+) image of $3^{\text {rd }}$ January 2002 and Landsat image of $5^{\text {th }}$ January 2015 were downloaded from the United States Geological Survey (USGS) website (Table 1).

NDVI values were derived from the satellite data and used as proxy for vegetation in order to relate the degradation with climate variables of rainfall and temperature. NDVI is extensively used to appraise vegetation composition, structure, stratification, and distribution (Khan et al., 2016), giving a clear idea about the vigor of forest vegetation. NDVI has been frequently used for studying vegetation dynamics because it is correlated with the photosynthetic capacity, leaf area index (LAI), biomass, and net productivity (Ding et al., 2007).

NDVI is one of the most commonly used vegetation indices for estimating leaf area index (LAI) and primary production (Potithep et al., 2010; Fan et al., 2008). Literature has shown that NDVI infers the presence of vegetation on the basis of the ratio of near infrared (NIR) reflectance and visible red (R) reflectance (Jiang et al., 2006; Xavier and Vettorazzi, 2004). High reflectance is observed in the NIR region because of the cellular structure of the leaves and low reflectance in the $\mathrm{R}$ region because of absorption due to chlorophyll pigments in the visible region (Ganie and Nusrath, 2016; CEGIS, 2015; Ozyavuz et al., 2015). The NDVI is correlated with certain biophysical properties of the vegetation canopy such as LAI, fractional vegetation cover, vegetation conditions, and biomass (Jiang et al., 2006; Meneses-Tovar, 2012).

To determine the correlation between climate variability and vegetation degradation, average weather data of rainfall and temperature were obtained from the Institute of Ecology of the Obafemi Awolowo University (Table 2).

\subsection{Analyses}

\subsubsection{Trend of Forest Degradation}

A combination of supervised image classification (to determine the land use and land cover) and Normalized Differential Vegetation Index (NDVI) were used to analyze the trend of forest degradation. Analysis of the time series of land use and land cover changes and NDVI were conducted. False color composites of the images were created using near-infrared, red and green bands of each of the

Table 1. Satellite data used in the study.

\begin{tabular}{cccc}
\hline Satellite & Sensor & Acquisition Date & Sources \\
\hline Landsat 5 & Thematic Mapper (TM). & 5 January 1986 & USGS \\
Landsat 7 & Enhanced Thematic Mapper plus (ETM+) & 3 January 2003 & USGS \\
Landsat 8 & Operational Land Imager (OLI) & 5 January 2014 & USGS \\
\hline
\end{tabular}


Table 2. Climate data.

\begin{tabular}{cccccc}
\hline Station & Year & Max Temp & Min Temp & Precipitation & Sources \\
\hline \multirow{3}{*}{ Ondo } & 1986 & 10.860 & 7.755 & 2095.1 & $\begin{array}{c}\text { Institute } \\
\text { of Ecology, } \\
\text { Obafemi }\end{array}$ \\
& 2002 & 9.546 & 6.853 & 1.355 .5 & Awolowo University \\
\hline
\end{tabular}

images using bands 4, 3 and 2 for each of the three time intervals, and a subset image of the study area extracted. Supervised classification using maximum likelihood algorithm was performed, the land use and land cover categories identified in the study area include cultivated land, forest, settlement and water. Cultivated land includes cultivated and fallow farmland, settlement includes built-up areas and bare-surfaces, and forest includes secondary vegetation, mature plantation and dense tropical forest, while the class categorized as water includes streams and rivers.

With the image analysis extension in ArcGIS environment, the three-time frame subset images were used to create three NDVI maps. The NDVI is an indicator of vegetation health, hence degradation of the vegetation must be reflected in a decrease in the value of the NDVI. Change in forest cover was determined through composite analysis of NDVI images for the relevant years. A disturbance in a vegetation community is therefore reflected in a corresponding fall in the value of NDVI.

The NDVI is calculated from these individual measurements as shown:

$$
\text { NDVI }=\text { NIR }- \text { RED/NIR }+ \text { RED }
$$

where NIR is the reflectance in the near infrared spectrum and RED is the reflectance in the red range of the spectrum (Mulbah Jr., 2013). NDVI values were calculated by combining bands 4 (near infrared) and 3 (visible red) for Landsat TM and ETM+ and bands 5 (near infrared) and 4 (visible red) for Landsat OLI in ArcGIS environment and imputing their values in the NDVI formula and then differencing of the values was carried out to detect change. Differencing involved the subtraction of 2002 NDVI values from the 1986 values, 2015 values from 1986 values and 2015 values from 2002 values. The density of vegetation (NDVI) at a certain point of the image is equal to the difference in the intensities of reflected light in the red and near infrared image divided by the sum of these intensities. Typically, NDVI values range from -1 to +1 , with negative values representing clouds, water and snow. Values close to zero represent rocks and bare soil while very small values ( 0.1 or less) represent empty areas of rocks, sand and snow. Moderate values (0.2 to 0.3$)$ indicate shrubs and meadows while large values ( 0.6 to 0.8$)$ represent temperate and tropical forests. NDVI values were calculated and correlated to land use types.

\subsubsection{Correlation between Forest Degradation and Climate Variability}

Descriptive and inferential statistical methods were used to analyze the data in 
order to establish a relationship between degradation and climate variability. Correlation analysis was performed to evaluate the nature and the strength of the linear relationship between NDVI and the climatic variables. NDVI is a good indicator of the ability of vegetation to absorb radiation (Wang et al., 2003). Linear regression analysis was employed to determine the correlation between NDVI in the different years (1986, 2002 and 2014) and the climate data. Rainfall data and temperature data were plotted in Microsoft Excel and the relationship between forest degradation, rainfall and temperature were identified. In correlation analysis, the magnitude of the correlation coefficient indicates the strength of the relationship. For example, a correlation of $\mathrm{R}^{2}=0.9$ suggests a strong, positive correlation between two variables while a correlation coefficient $R^{2}=-0.2$ suggests a weak, negative correlation. A correlation close to zero suggests no linear correlation between the two variables.

\section{Results and Discussion}

\subsection{Results}

This section presents the results of the evaluation of the trend of vegetation degradation between 1986, 2002 and 2014 in the Oluwa forest and result of the correlation analysis between forest degradation and weather variability.

\subsubsection{Trend of Forest Degradation}

Spatial and temporal variations in vegetation were examined in relation to rainfall and temperature. Landsat imageries of 1986, 2002 and 2014 were classified to determine the rate of vegetation degradation in the Oluwa forest. The area extent of each of the five distinct land use and land cover categories for each of the years under review were determined. Extensive ground-truthing exercises were carried out to verify the present condition in terms of land use and land cover. Table 3 presents the different classes of land use analyzed in 1986 while Figure 2 shows the result of the supervised classification of 1986.

The land use and land cover status of 2002 are given in Table 4 while Figure 3 shows the classified image of 2002.

Table 3. Land use classes (1986).

\begin{tabular}{cccc}
\hline S.N & Land use land cover & Status (Area) $($ Sq. $\mathrm{km})$ & $\%$ \\
\hline 1 & Dense Forest & 396.049 & 60.7104 \\
2 & Sparse Forest (Sec veg) & 49.8262 & 0.763787 \\
3 & Cultivation & 32.8423 & 5.0344 \\
4 & Built-up Area & 6.93355 & 1.06285 \\
5 & Bare surfaces & 8.68481 & 1.3313 \\
6 & Others & 202.865 & 31.0972 \\
\end{tabular}




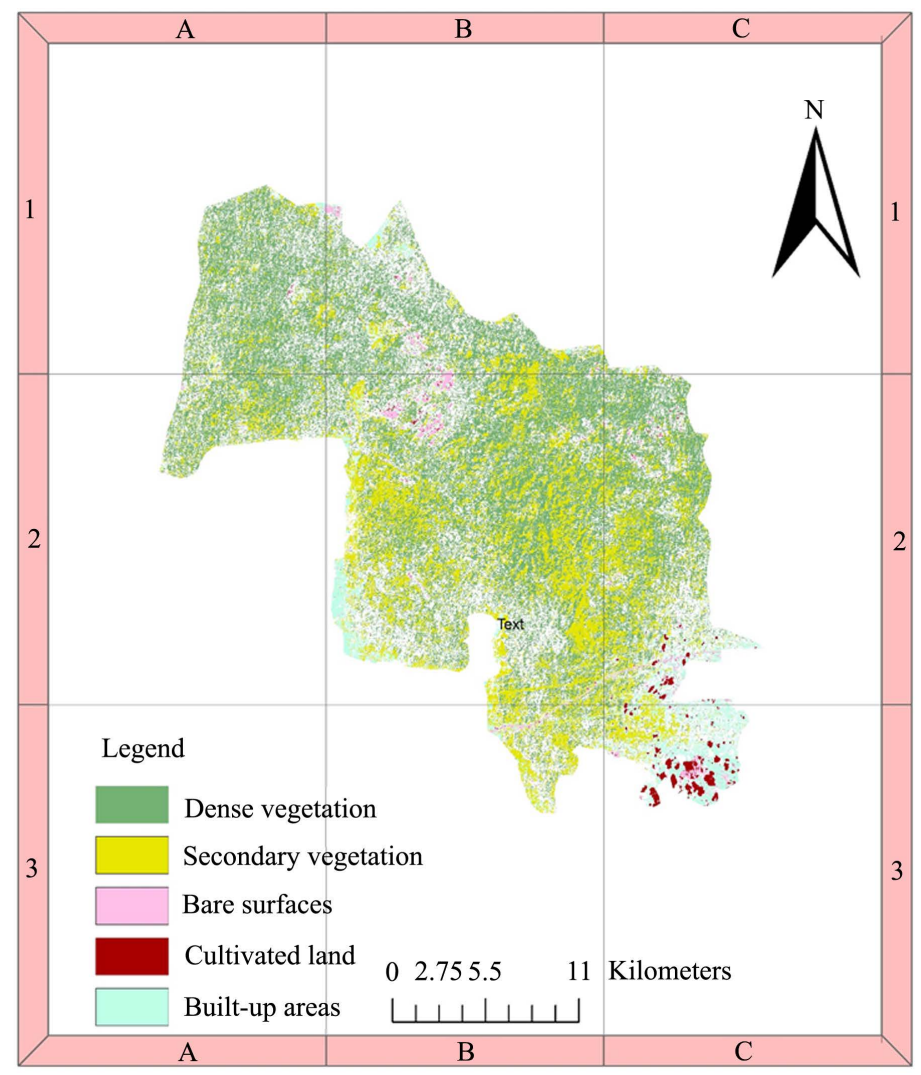

Figure 2. Classified image, 1986.

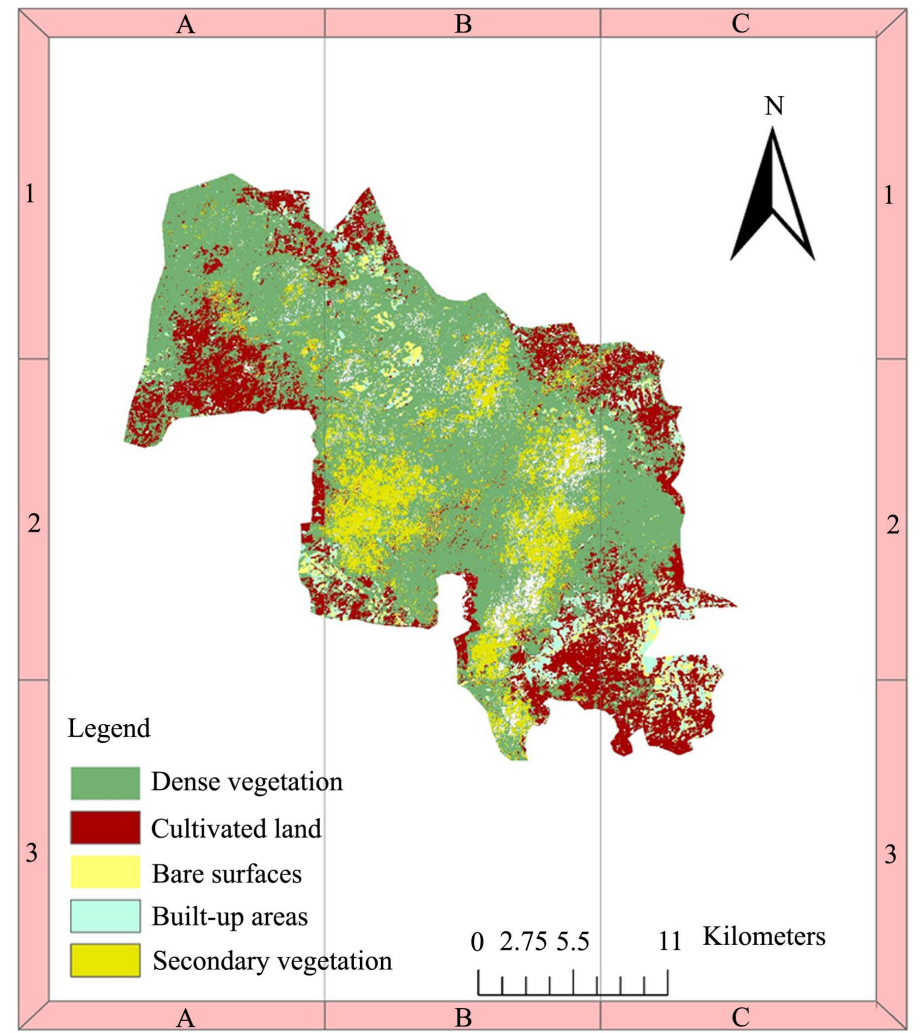

Figure 3. Classified image, 2002. 
Table 4. Land use classes (2002).

\begin{tabular}{cccc}
\hline S.N & Land use Land cover & Status (Area) $(\mathrm{Sq} \cdot \mathrm{km})$ & $\%$ \\
\hline 1 & Dense vegetation & 360.458 & 55.2556 \\
2 & Sparse forest (Sec veg) & 71.4892 & 10.9588 \\
3 & Built-up areas & 38.4095 & 5.8879 \\
4 & Bare surfaces & 16.8535 & 2.58352 \\
5 & Cultivation & 136.087 & 20.8612 \\
6 & Others & 29.04912 & 4.45302. \\
& Total & 652.34632 & 100 \\
\hline
\end{tabular}

Using the Operational Landsat Imagery of 2014, classification was performed as shown in Figure 4 and the various classes in Table 5.

Change detection analysis was also performed to determine the overall changes (in percentages) of the land use and land cover in the study area. Table 6 provides the changes that have occurred over the years under consideration.

The NDVI values were also employed to show changes in the forest land use and land cover of the study area. The NDVI is an indicator that shows areas affected by degradation and areas that have healthy vegetation coverage. In order to understand the results better and to make a healthier comparison, the NDVI values were re-classified, applied for each image. Figures 5-10 represent NDVI images and values for the various years and show areas of low and high vegetation cover.

\subsubsection{Correlation between Forest Degradation and Climate Variability} The NDVI values generated and presented in the preceding section was employed to determine whether a relationship exists between forest degradation taking place in the forest reserve and variation in climate parameters of rainfall and temperature (Table 7). Inferential statistics using the regression analysis technique was also performed to examine the quantitative relationship between NDVI and the major climatic variables concerned as shown in Table 8. The NDVI values of the different time periods and the relevant climatic elements were used to show the relationship between vegetation cover in the study area.

\subsection{Discussion}

\subsubsection{Trend of Forest Degradation}

According to the classification results of the imageries, the trend of forest degradation in the study area fluctuates. Five major land uses were determined after classification. The result shows that in 1986 forest was the major land use followed by cultivated land or agricultural land and built-up surfaces (settlement), secondary vegetation, bare surfaces (rocks and soil) and others. In 1986, dense forest occupied $60.7 \%$ of total land and was the major land use and land cover of the study area. Cultivation consisted of $5.0 \%$, bare surfaces $1.3 \%$, sparse forest or secondary vegetation $0.7 \%$, built-up area $1.0 \%$, and other land uses 


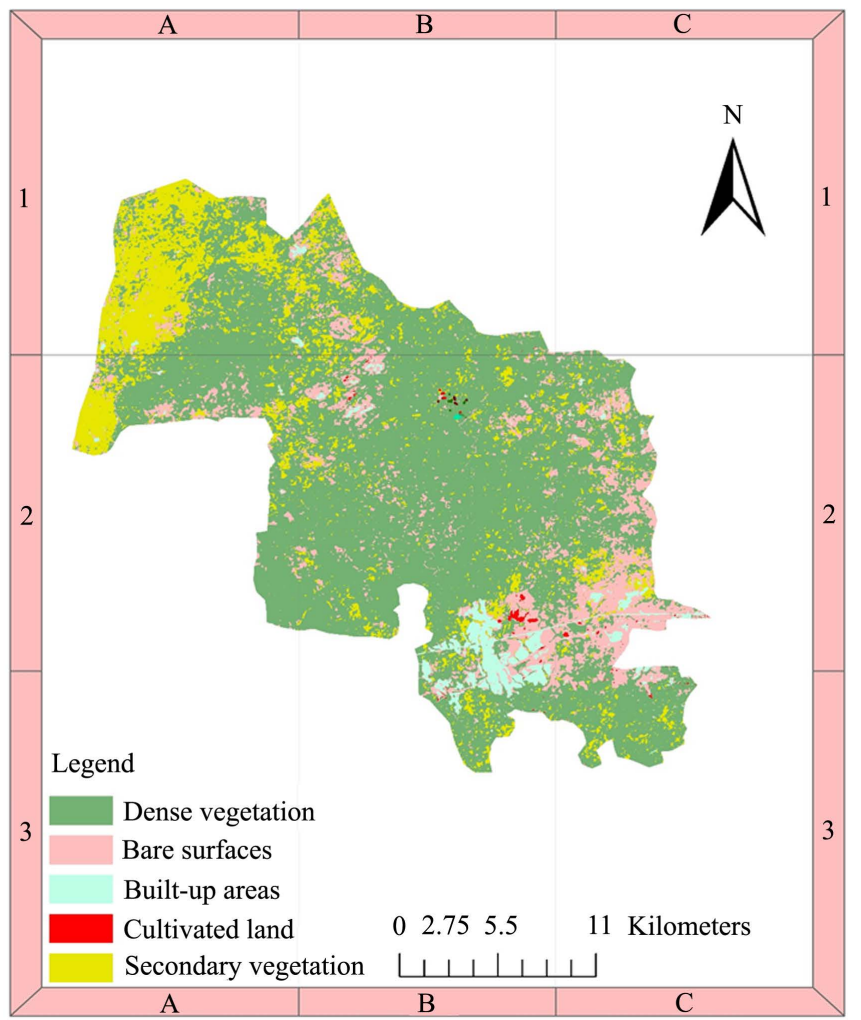

Figure 4. Classified image, 2014.

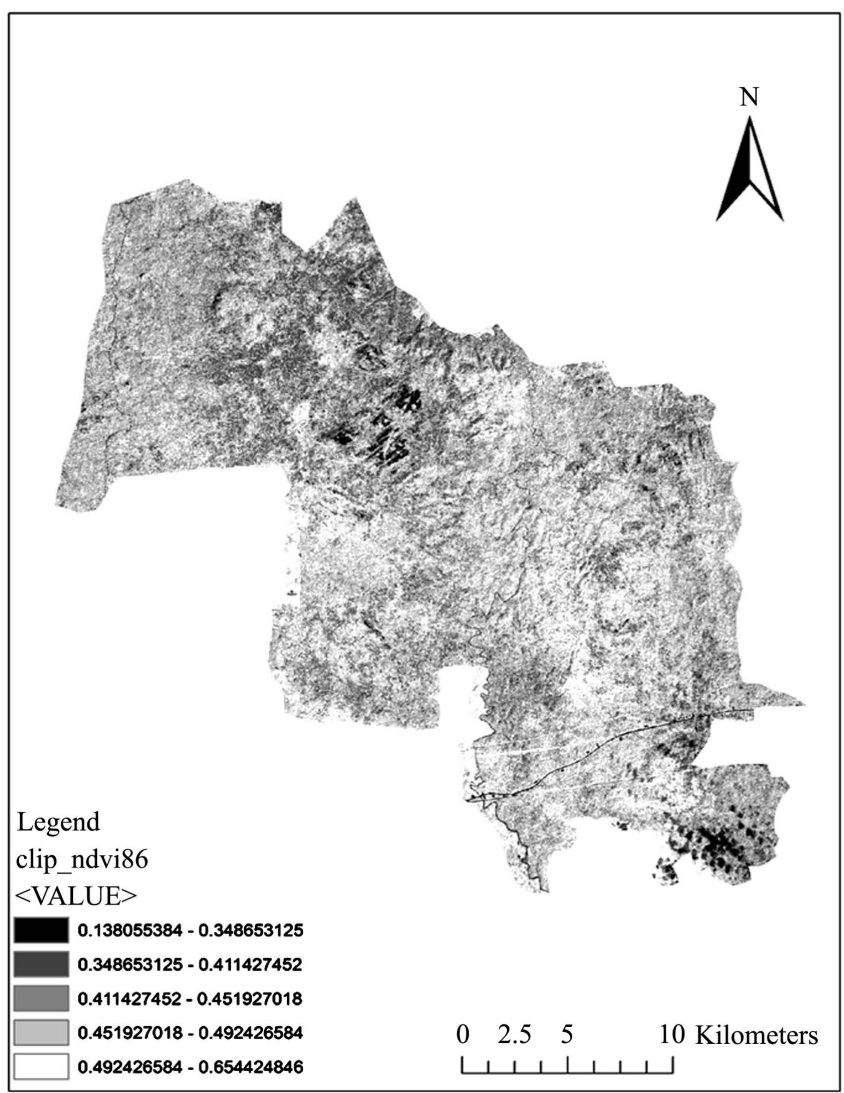

Figure 5. NDVI image, 1986. 


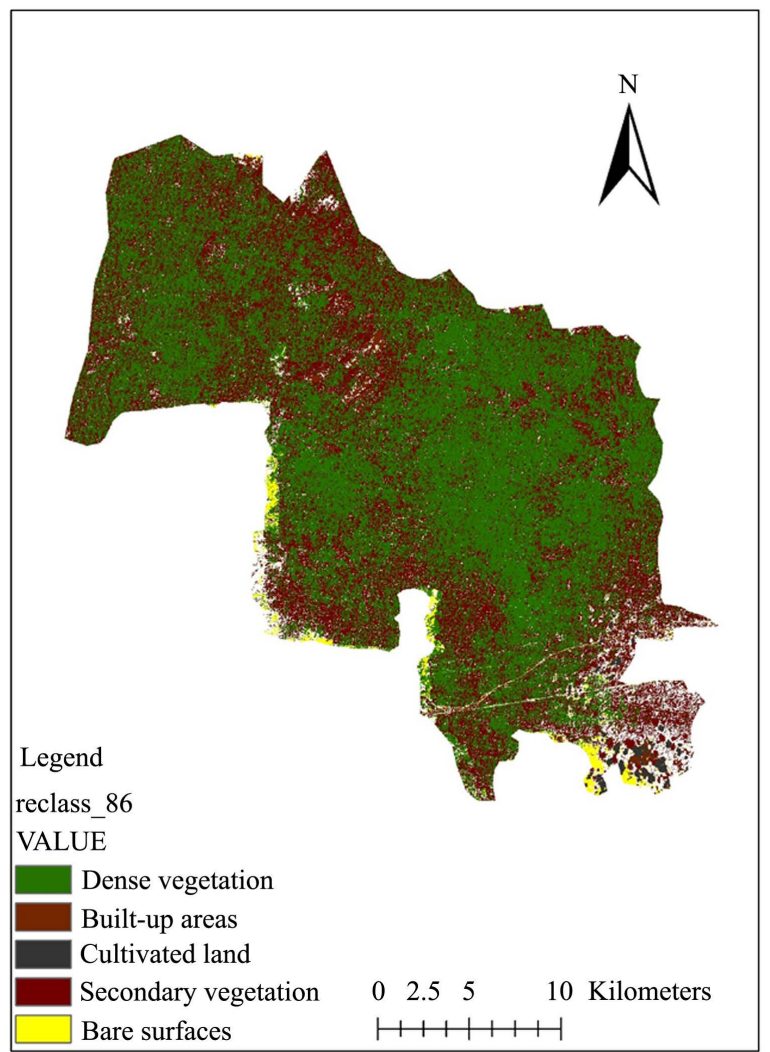

Figure 6. Reclassified NDVI image, 1986.

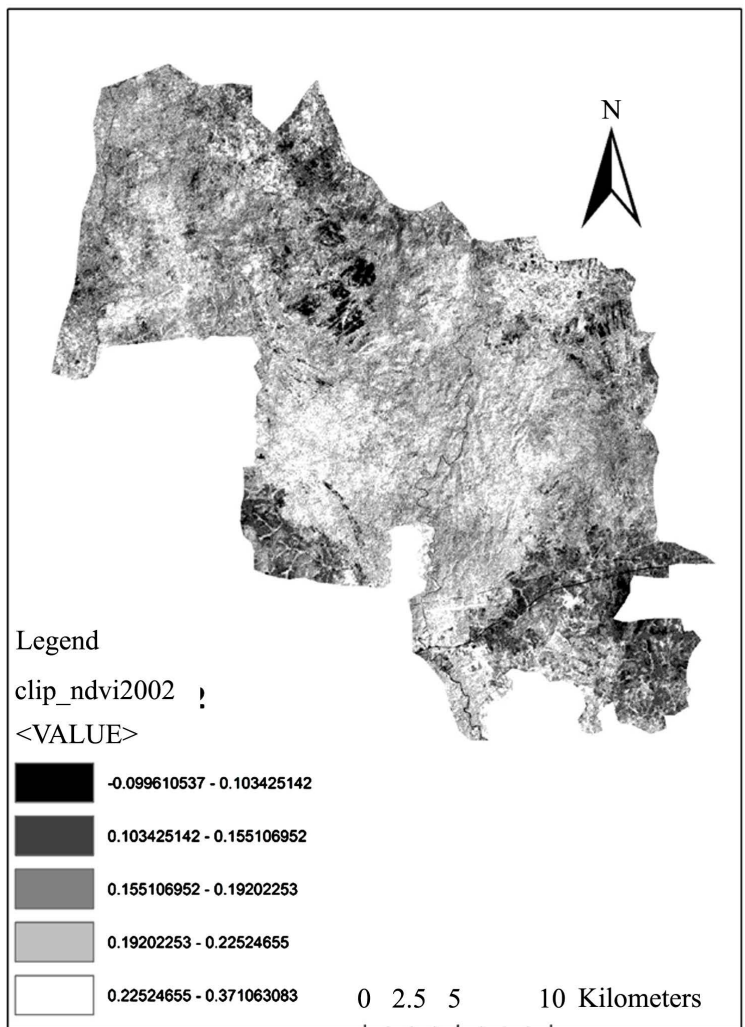

Figure 7. NDVI image, 2002. 


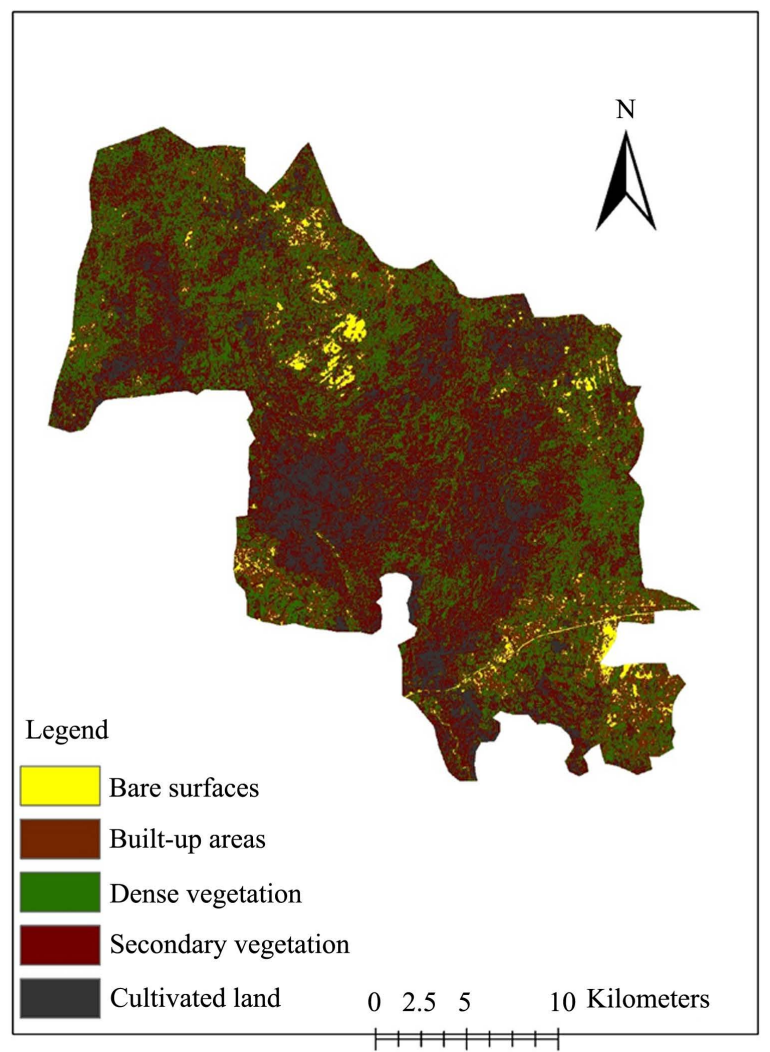

Figure 8. Reclassified NDVI image, 2002.

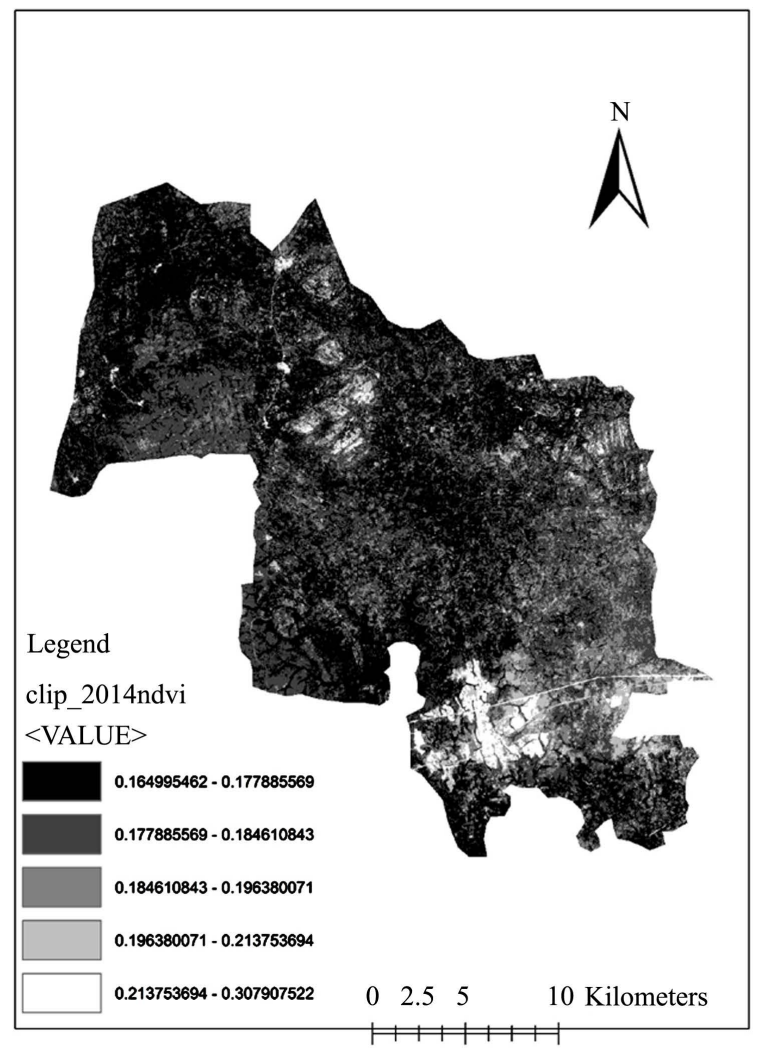

Figure 9. NDVI image, 2014. 


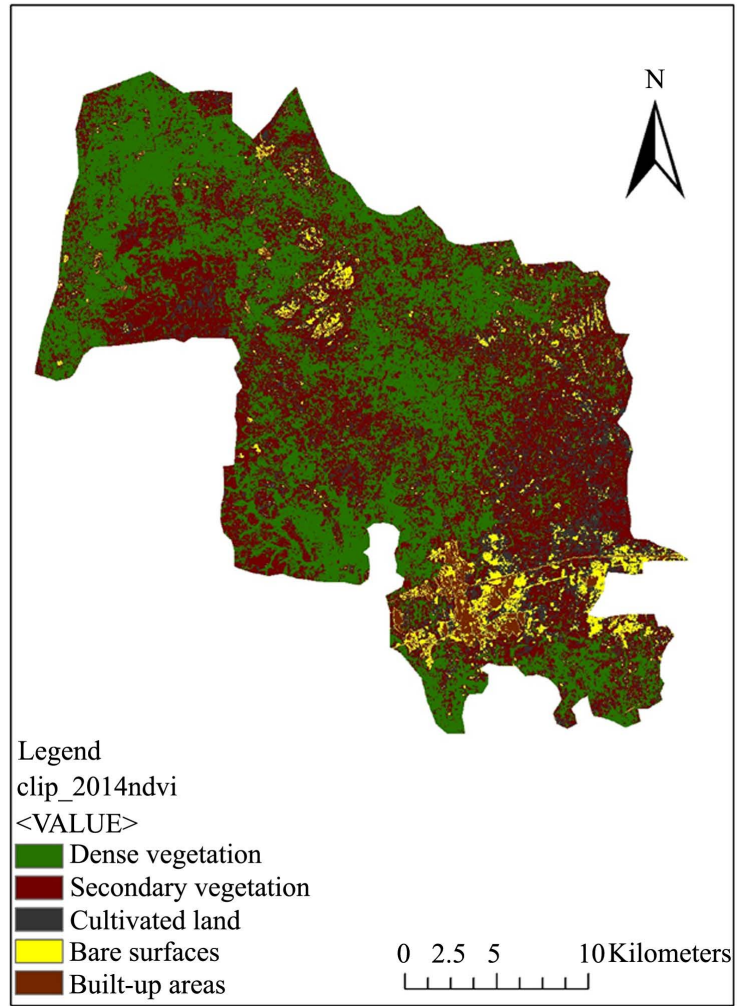

Figure 10. Reclassified NDVI image, 2014.

Table 5. Land use and land cover classes (2014).

\begin{tabular}{cccc}
\hline S.N & Land use land cover & Status (Area) $(\mathrm{Sq} \cdot \mathrm{km})$ & $\%$ \\
\hline 1 & Dense vegetation & 447.703 & 68.6289 \\
2 & Sparse forest (Sec Veg) & 84.1961 & 12.9065 \\
3 & Cultivation & 100.436 & 15.396 \\
4 & Built-up areas & 18.7558 & 2.8751 \\
5 & Bare Surfaces & 1.2624 & 0.193515 \\
& Total & 652.3533 & 100 \\
\hline
\end{tabular}

Table 6. Change detection analysis.

\begin{tabular}{|c|c|c|c|c|c|c|}
\hline $\begin{array}{c}\text { Forest Land } \\
\text { use land } \\
\text { cover }\end{array}$ & $\begin{array}{c}1986 \\
\text { Status Area } \\
(\mathrm{Sq} \cdot \mathrm{km})\end{array}$ & $\begin{array}{c}\text { Class \% } \\
1986\end{array}$ & $\begin{array}{c}2002 \\
\text { Status Area } \\
(\mathrm{Sq} \cdot \mathrm{km})\end{array}$ & $\begin{array}{c}\text { Class \% } \\
2002\end{array}$ & $\begin{array}{c}2014 \\
\text { Status Area } \\
(\mathrm{Sq} \cdot \mathrm{km})\end{array}$ & $\begin{array}{c}\text { Class \% } \\
2014\end{array}$ \\
\hline Dense forest & 396.049 & 60.7104 & 360.458 & 55.2556 & 447.703 & 68.6289 \\
\hline Secondary vegetation & 49.8262 & 0.763787 & 71.4892 & 10.9588 & 84.1961 & 12.9065 \\
\hline Bare surface & 8.68481 & 1.3313 & 16.8535 & 2.58352 & 1.2624 & 0.193515 \\
\hline Built-up area & 6.93355 & 1.06285 & 38.4095 & 5.8879 & 18.7558 & 2.8751 \\
\hline Cultivation & 32.8423 & 5.0344 & 136.087 & 20.8612 & 100.436 & 15.396 \\
\hline Others & 202.865 & 31.0972 & 29.04912 & & & \\
\hline Total & 652.4 & & 652.4 & & 652.4 & \\
\hline
\end{tabular}


Table 7. Relationship between vegetation and climate parameters.

\begin{tabular}{cccc}
\hline Years & Precipitation & Average temperature & Forest area \\
\hline 1986 & 2095.1 & 9307.5 & 652.4 \\
2002 & 1355.5 & 8199.5 & 652.3 \\
2014 & 1756 & 10212.5 & 652.4 \\
\hline
\end{tabular}

Table 8. Correlation between forest degradation, rainfall and temperature.

\begin{tabular}{ccccc}
\hline Year & Rainfall & Average Temperature & Forest & \\
\hline 1986 & 2095.1 & 9307.5 & 652.4 & \\
2002 & 1355.5 & 8199.5 & 652.3 & \\
2014 & 1756 & 10212.5 & 652.4 & 0.58886 \\
\hline
\end{tabular}

(water bodies, grassland, barren land, ponds and orchard) occupied 31.0\%. For 2002, dense forest still remained the major land use and land cover consisting of $55.2 \%$ of total land. Secondary forest increased in area occupying $11 \%$, cultivated land also increased to $21 \%$. Built up areas increased to $6 \%$ and there was also an increase in bare surfaces to $2.6 \%$. For 2014, dense forest remained the major land use land cover having an increase of $13.4 \%$ from 2002 to 2014 . Secondary vegetation increased by $2 \%$ from 2002 to 2014 . There was a decrease in bare surfaces of $2.4 \%$, and built-up areas also decreased by $3 \%$ from 2002 to 2014 . Cultivated land decreased by $5.5 \%$.

In summary, from the change detection analysis (Table 6), dense vegetation decreased from $60.7 \%$ in 1986 to $55.25 \%$ in 2002 due to illegal human activities in the reserve but increased to $68.6 \%$ in 2014 . This may be attributed to the reforestation (using gmelina arborea trees) efforts of the authorities managing the reserve. Secondary vegetation continuously increased from $0.76 \%$ in 1986 to $10.95 \%$ in 2002 and 12.91 in 2014 . This may be attributed to reforestation and the fact that illegal logging was concentrated on larger trees found in densely forested areas. Bare surface increased from $1.3 \%$ in 1986 to $2.5 \%$ in 2002 but reduced to $0.1 \%$ in 2014 most probably as a result of the reforestation efforts. Built up areas that increased from $1.0 \%$ in 1986 to $5.8 \%$ in 2002 due to settlement encroachment reduced to $2.8 \%$ in 2014 most probably due to stricter monitoring of the reserve. Cultivated land that increased from $5.0 \%$ in 1986 to $20.8 \%$ in 2002 due to farm encroachment and illegal logging reduced to $15.3 \%$ in 2014 also probably due to stricter monitoring.

The reclassified NDVI images of the time periods analyzed support the trend of degradation analyzed above. Very low values of NDVI ( 0.1 and below) correspond to barren areas or bare surfaces. Moderate values represent shrub and grassland and cultivated land ( 0.2 to 0.3 ), while high values indicate dense forests $(0.6$ to 0.8$)$. This result shows that a disturbance or degradation in the forest reserve is reflected in a corresponding fall in the values of the NDVI. Degradation was observed in 1986 and 2002 related to low NDVI values while there 
was an increase in NDVI values in 2014, which means that vegetation condition improved in the reserve. An improvement in the condition of vegetation as indicated by an increase in the values of NDVI results in an increase in rainfall and a decrease in temperature. This finding is consistent with a study conducted by Ning et al. (2015) which found that precipitation increases and temperature reduces with an increase in the values of NDVI in the Loess plateau in China. The increase in vegetation in the present study can be attributed to massive reforestation efforts undertaken by authorities of the forest reserve. This finding is also consistent with another study conducted by Tovar (2009) which analyzed the NDVI to detect degradation of forest coverage in Mexico and found that decrease in the values of NDVI was an indication of degradation or deforestation, depending on the degree of decrease. Conversely, increase in the NDVI values were related to areas of recovery of vegetation to disturbance or a natural increase of biomass.

\subsubsection{Correlation between Forest Degradation and Climate Variability} The NDVI was used as an indicator to measure the relationship between forest degradation, temperature and rainfall in the study area. The climate of the study area can be described as humid tropical. Mean annual rainfall ranges from 1200 $\mathrm{mm}$ to $1450 \mathrm{~mm}$ and temperatures are high throughout the year with a mean of about $27^{\circ} \mathrm{C}$ and annual range of about $3^{\circ} \mathrm{C}$. Calculating the relationship between rainfall and temperature and NDVI within the years 1986, 2002 and 2014 established a correlation coefficient of 0.588 (Table 8), which is a positive correlation. This finding is similar to a study conducted by Lamchin et al. (2018) to determine the long-term trend and correlation between vegetation greenness and climate variables in Asia based on satellite data. The study utilized NDVI data derived from remote sensing vegetation data and climate data (rainfall and temperature) of the same period as the NDVI. The study performed trend analysis for vegetation greenness, and correlation and linear analysis for climate variables. Findings showed that the annual NDVI has a positive relationship with the annual rainfall and temperature.

The positive correlation in the present study means that when NDVI values increase, rainfall increases. And an increase in NDVI values is also reflected in a decrease in temperature. This finding is also consistent with a study conducted by Kundu et al. (2017) in which temporal responses of NDVI to rainfall was analyzed. The study employed linear regression to analyze the statistical relationship between NDVI and rainfall and their trends. The result showed that the correlation between NDVI and rainfall for the sites revealed consistent increasing NDVI with increasing trend of rainfall (a positive correlation). Another study conducted by Ning et al. (2015) analyzed NDVI variation and its responses to climate change on the northern Loess plateau of China from 1998 to 2012. The study found that annual NDVI showed an upward trend, with precipitation increasing and temperature showing a decrease. This is consistent with the findings of the present study. A correlation coefficient greater than 0.8 will categori- 
cally establish a linear relationship between degradation and climate variables. In the present study, a coefficient of correlation of $\mathrm{R}^{2}=0.58$ was established which is merely a moderate uphill (positive) relationship but not strong enough to make a generalization. This indicates that low intensity degradation is taking place in the forest reserve.

\section{Conclusion}

Forests play important roles in the sustainability of the natural environment and humanity. They preserve and sustain biodiversity thereby preventing species loss and maintaining ecological balance. People also depend on forest products for their livelihoods. Forests also affect climate because they are important in maintaining the water cycle, sequester carbon, and by absorbing direct solar radiation. It is therefore crucial to prevent forest loss. Nigeria, has, however, been losing its forests over the years. Most studies on forests in Nigeria have tended to focus on the impact and effect of climate on vegetation and productivity. This study however set out to investigate the effect of forest degradation on climate variability using rainfall and temperature as weather parameters of interest.

Findings show that dense forest reduced in 2002 but increased in 2014. The reduction from 1986 to 2002 is attributed to an increase in demand for forest products such as wood for construction, clearing of the forest for agriculture, illegal logging and gathering of fuel wood. The increase in dense forest observed in 2014 was due to preventive measures put in place by the authorities of the reserve and to reforestation efforts. There has been a continued increase in secondary vegetation, bare surfaces have increased between 1986 and 2002, while there was a reduction in 2014. Built-up areas increased between 1986 and 2002 but reduced in 2014. Cultivated land (plantation agriculture) increased between 1986 and 2002 but reduced in 2014. These change detection analyses are supported by NDVI values analyzed and also reflected in the areas per square meter covered by these land uses. The research therefore concludes that degradation of the reserve was taking place but has been halted by proactive intervention of the authorities, hence activities such as reforestation when undertaken can halt forest degradation.

Results from the correlation analysis show a correlation coefficient $\mathrm{R}^{2}=0.58$. This shows that a positive correlation exists between the degradation of the forest reserve and climate parameters of rainfall and temperature. The research therefore concludes that degradation of the forest reserve (though low intensity) through illegal logging and fragmentation via settlement and subsistence agriculture have deleterious consequences on rainfall and temperature. However, the correlation coefficient $\mathrm{R}^{2}=0.58$ is not strong enough for this study to make a generalization about the climate of the surrounding area. Further research that encompasses the surrounding communities and environment may be necessary before a generalization can be made.

Countries and governments can, however, reduce the adverse effects and impacts of deforestation and degradation of forests by taking proactive measures 
that will prevent the loss or alteration of forests. For example, among other measures, they can provide funding for programmes designed to promulgate and enforce environmental legislation, and support economic alternatives to extensive forest clearing for timber, fuel wood, and other forest products. Governments can also build institutional capacities concerned with forest preservation in remote forest areas and enhance the competencies and capabilities of forest managers to monitor and enforce best practices in forest reserves.

\section{Conflicts of Interest}

The authors declare no conflicts of interest regarding the publication of this paper.

\section{References}

Archana, K. (2013). Impact of Deforestation on Climate. IOSR Journal of Environmental Science, Toxicology and Food Technology, 4, 24-28. https://doi.org/10.9790/2402-0422428

CEGIS (2015). Advanced Remote Sensing and GIS. Training Manual Developed by CEGIS, USFS, and BFD.

Centre for People and Forests-CPF (2012). Climate Change, Forests, and You. Grassroots Capacity Building for REDD+ in the Asia-Pacific Region.

Ding, M., Zhang, Y., Liu, L., Zhang, W., Wang, Z., \& Bai, W. (2007). The Relationship between NDVI and Precipitation on the Tibetan Plateau. Journal of Geographical Sciences, 17, 259-268. https://doi.org/10.1007/s11442-007-0259-7

Ekanade, O. (1997). Hill-Slope Agro-Systems and Their Implications on Environmental Systems in Rural Southwestern Nigeria. Agriculture, Ecosystems, and Environment, 61, 97-102. https://doi.org/10.1016/S0167-8809(96)01109-7

Fan, L., Gao, Y., Bruck, H., \& Bernhofer, Ch. (2008). Investigating the Relationship between NDVI and LAI in Semi-Arid Grassland in Inner Mongolia Using In-Situ Measurements. Theoretical and Applied Climatology, 95, 151-156.

https://doi.org/10.1007/s00704-007-0369-2

FAO-Food and Agriculture Organization (2005). Proceedings: Third Expert Meeting on Harmonizing Forest-Related Definitions for Use by Various Stakeholders. Rome, 17-19 January 2005.

Food and Agriculture Organization (2011). Assessing Forest Degradation: Towards the Development of Globally Applicable Guidelines. Forest Resources Assessment Working Paper 177. Rome.

Ganie, M. A., \& Nusrath, A. (2016). Determining the Vegetation Indices (NDVI) from Landsat 8 Satellite Data. International Journal of Advanced Research, 4, 1459-1463. https://doi.org/10.21474/IJAR01/1348

Gbile, Z. O., \& Adesina, S. K. (1987). Nigerian Flora and Its Pharmaceutical Potential. Journal of Ethnopharmacology, 19, 1-16. https://doi.org/10.1016/0378-8741(87)90135-8

Jiang, Z., Huete, A. R., Chan, J., Chan, Y., Li, J., Yan, G., \& Zhang, X. (2006). Analysis of NDVI and Scaled Difference Vegetation Index Retrievals of Vegetation Fraction. Remote Sensing of Environment, 101, 366-378. https://doi.org/10.1016/j.rse.2006.01.003

Khan, I. A., Arsalan, M. H., Siddiqut, M. F., Kiran, N., \& Ajaib, M. (2016). Short-Term 
Drought Assessment in Pakistan and Adjoining Areas by Remote Sensing MODIS-NDVI Data: A Potential Consequence of Climate Change. Pakistan Journal of Botany, 48, 1887-1892.

Kundu, A., Denis, D. M., Patel, N. R., \& Dutta, D. (2017). A Geospatial Study for Analyzing Temporal Responses of NDVI to Rainfall. Singapore Journal of Tropical Geography, 39, 107-116. https://doi.org/10.1111/sjtg.12217

Lamchin, M., Lee, W. K., Wang, S. W., Lim, C. H., Song, C., \& Sung, M. (2018). Long-Term Trend and Correlation between Vegetation Greenness and Climate Variables in Asia Based on Satellite Data. Science of the Total Environment, 618, 1089-1095. https://doi.org/10.1016/j.scitotenv.2017.09.145

Loreau, M., Naeem, S., Inchausti, P., Bengtsson, J., Hector, A., Grime, P. J., \& Bernhard, S. (2001). Biodiversity and Ecosystem Functioning: Current Knowledge and Future Challenges. Science, 294, 804-808. https://doi.org/10.1126/science.1064088

Meneses-Tovar, C. L. (2012). NDVI as Indicator of Degradation. Unasylva 238, 62, 39-46.

Mulbah Jr., D. M. (2013). An Assessment of the Effects of Climate Variability on Forest Cover in Liberia. Unpublished MSc. Dissertation, Nairobi: University of Nairobi.

Ning, T., Liu, W., Lin, W., \& Song, X. (2015). NDVI Variation and Its Responses to Climate Change on the Northern Loess Plateau of China from 1998 to 2012. Advances in Meteorology, 2015, Article ID: 725427. https://doi.org/10.1155/2015/725427

Orimoogunje, O. O. I. (2005). The Impact of Land Use Dynamics on Oluwa Forest Reserve in Southwestern Nigeria. Unpublished Ph.D. Thesis, Ile-Ife: Department of Geography, Obafemi Awolowo University.

Orimoogunje, O. O. I. (2014). Forest Cover Changes and Land Use Dynamics in Oluwa Forest Reserve, Southwestern Nigeria. Journal of Landscape Ecology, 7, 25-44. https://doi.org/10.2478/jlecol-2014-0014

Ozyavuz, M., Bilgili, B. C., \& Salici, A. (2015). Determination of Vegetation Changes with NDVI Method. Journal of Environmental Protection and Ecology, 16, 264-273.

Potithep, S., Nasahara, N. K., Muraoka, H., Nagai, S., \& Suzuki, R. (2010). What Is the Actual Relationship between LAI and VI in a Deciduous Broadleaf Forest? International Archives of the Photogrammetry, Remote Sensing and Spatial Information Science, $38,609-614$.

Salami, A. T., Ekanade, O., \& Oyinloye, R. O. (1999). Detection of Forest Reserve Incursion in Southwestern Nigeria from a Combination of Multi-Data Aerial Photographs and High Resolution Satellite Imagery. International Journal of Remote Sensing, 20, 1487-1497. https://doi.org/10.1080/014311699212579

Sanderson, M., Santini, M., Valentini, R., \& Pope, E. (2012). Relationship between Forests and Weather. Met Office Hadley Centre, EC Directorate of the Environment.

Senior, R. A., Hill, J. K., del Pliego, P. G., Goode, L. K., \& Edwards, D. P. (2017). A Pantropical Analysis of the Impacts of Forest Degradation and Conversion on Local Temperature. Ecology and Evolution, 7, 7897-7908. https://doi.org/10.1002/ece3.3262

Tejasmi, G. (2007). Strengthening Monitoring, Assessment and Reporting on Sustainable Forest Management in Asia (GCP/INT/988/JPN). Manual on Deforestation, Degradation, and Fragmentation Using Remote Sensing and GIS. Forestry Department, Food and Agriculture Organization (FAO) of the UN, MAR-SFM Working Paper 5/2007.

Tovar, C. L. M. (2009). Analysis of the Normalized Differential Vegetation Index for the Detection of Degradation of Forest Coverage in Mexico, 2000-2009. Forest Resources Assessment Working Paper 173: Case Studies on Measuring and Assessing Forest Degradation. 
Udoakpan, U. I. (2013). An Evaluation of Wood Properties of Pinus caribeae (Morelet) in Oluwa Forest Reserve, Ondo State, Nigeria. Ethiopian Journal of Environmental Studies and Management, 6, 159-169. https://doi.org/10.4314/ejesm.v6i2.6

Wang, J., Rich, P. M., \& Price, K. P. (2003). Temporal Responses of NDVI to Precipitation and Temperature in the Central Great Plains, USA. International Journal of Remote Sensing, 29, 2345-2364. https://doi.org/10.1080/01431160210154812

Xavier, A. C., \& Vettorazzi, C. A. (2004). Monitoring Leaf Area Index at Watershed Level through NDVI from Landsat 7/ETM+ Data. Scientia Agricola, 61, 243-252. https://doi.org/10.1590/S0103-90162004000300001 